\title{
A CRÍTICA HERMENÊUTICA DO DIREITO E A TEORIA DA ARGUMENTAÇÃO DE ATIENZA: CONVERGENCIAS E DIVERGÊNCIAS SOBRE O RACIOCÍNIO JURÍDICO
}

\author{
Lenio Luiz Streck ${ }^{1}$
}

\section{Resumo}

Pensar sobre o raciocínio jurídico é uma tarefa necessária e contínua para os advogados, especialmente para os teóricos do direito. Desta forma, e com grande destaque são as reflexões de Manuel Atienza. Sua teoria da argumentação jurídica (TAJ) é apresentada como um dos modelos teóricos mais importantes dentro de uma tradição analítica da análise do Direito. Por tudo isso, a existência de um diálogo sobre o seu pensamento é enriquecedor por ampliar as perspectivas de diferentes pontos de vista. A Crítica Hermenêutica do Direito (CHD) que desenvolvi está localizada em outro andar. Partindo de aportes filosóficos da fenomenologia hermenêutica que observa o jurídico como um fenômeno hermenêutico que pressupõe um espaço intersubjetivo de significados. Por estar em diferentes paradigmas filosóficos, a CHD e TAJ já tem um antagonismo de base, entretanto, algumas aproximações também são possíveis. Em este texto será levantado algumas divergências e convergências entre os dois projetos teóricos que têm como temas principais, entre outros: a) o raciocínio analítico-argumentativo; b) ponderação; c) a argumentação jurídica como um exercício de retórica; e d) a decisão judicial e as influências de moralidade.

Palavras-chave: Crítica Hermenêutica do Direito; Teoria da argumentação jurídica; raciocínio analíticoargumentativo; ponderação; decisão judicial.

\section{PALAVRAS INICIAIS}

Por muito tempo o raciocínio jurídico ficou limitado a um exercício teórico, sistemático, (meramente) analítico, como se o fenômeno jurídico coubesse apenas na episteme, no sentido aristotélico da palavra. Já no período do segundo pós-guerra esta perspectiva foi tida como insuficiente. Como responder a um estado de barbárie, juridicamente perpetrado, com modelos teóricos descritivistas que buscavam a todo custo afastar elementos justificatórios? Como resposta, o direito passou a ser também visto como razão prática (phronesis), em que para além da questão da validade a busca se concentrou na legitimidade.

\footnotetext{
${ }^{1}$ Pós-doutor pela Universidade de Lisboa. Professor titular do Programa de Pós-Graduação em Direito (Mestrado e Doutorado) da UNISINOS, na área de concentração em Direito Público. Professor permanente da UNESA-RJ, e visitante da Faculdade de Direito da Universidade de Coimbra - FDUC (Acordo Internacional Capes-Grices) e da Faculdade de Direito da Universidade de Lisboa. Membro catedrático da Academia Brasileira de Direito Constitucional - ABDConst. Presidente de Honra do Instituto de Hermenêutica Jurídica - IHJ (RS-MG). Membro da comissão permanente de Direito Constitucional do Instituto dos Advogados Brasileiros - IAB, do Observatório da Jurisdição Constitucional do Instituto Brasiliense de Direito Público - IDP, da Revista vol.09, nº. 04, Rio de Janeiro, 2016. pp. 2207-2226 2207
} 
Todavia, outros problemas se apresentaram, tais como: haveria algum modo de "controlar" ou dar objetividade a este tipo de raciocínio? Haveria procedimentos para tanto? Como se daria a aproximação entre direito e moral? Na tentativa de responder a estas indagações correntes contemporâneas do Direito estão a Teoria da Argumentação de Manuel Atienza e a Crítica Hermenêutica do Direito, que venho desenvolvendo.

Atienza se encontra em destaque no cenário acadêmico hodierno em decorrência de suas profícuas elaborações teóricas que, embora estejam assentadas em uma matriz diferente, temos que reconhecer o seu valor teórico e prático. O modo como o jurista espanhol (re)pensou o raciocínio jurídico foi a partir da teoria do discurso, mas especificamente, inserindo-se numa longa tradição de teorias argumentativas que remontam a nomes como os de Theodor Viehweg, Chaim Perelman, Stephen Toulmin, Neil MacCormick, Robert Alexy, dentre outros. Em síntese, dentro desta tradição as decisões judiciais alcançarão legitimidade/justificação se considerarem certas regras/procedimentos que guiariam um discurso racional.

Já a Crítica Hermenêutica do Direito (CHD), desenvolvida sob os aportes filosóficos da fenomenologia hermenêutica e da hermenêutica filosófica, caminha em sentido diverso. Reconhecendo o giro ontológicolinguístico, a linguagem deixa de ser um mero instrumento e passa a ser condição de possibilidade do nosso acesso ao mundo. Assim, constituímos e somos constituídos linguisticamente dentro de um inescapável horizonte histórico. Poderíamos dizer que, enquanto a teoria da argumentação centra sua preocupação no depois, na explicitação do compreendido, a CHD volta-se para o fundamento, à própria compreensão. Por isso, a primeira é analítica; a segunda, ontológica (não no sentido clássico).

Por procurarem dar respostas ao mesmo contexto contemporâneo, a TAJ formulada por Atienza e a CHD por mim elaborada apresentam algumas aproximações. No entanto, por se assentarem em pressupostos filosóficos diferentes, possuem também divergências. Sobre estas, este pequeno ensaio se debruçará, tendo como enfoque as 10 teses de Atienza ${ }^{2}$ sobre raciocínio jurídico, sobre os seguintes eixos norteadores: a) o raciocínio analítico-argumentativo; b) a ponderação; c) a argumentação jurídica como exercício retórico; e d) a decisão judicial e os influxos da moralidade.

\section{ENTRE HERMENÊUTICA E ARGUMNETAÇÃO: TESES, ANTÍTESES E SÍNTESES SOBRE O RACIOCÍNIO JURÍDICO}

Atienza, corretamente, entende que o fenômeno jurídico é complexo, o que dificulta, sobremaneira, o desenvolvimento de teorias que o abarquem em sua totalidade. Nesse sentido, aponta três perspectivas ou enfoques distintos para compreender o Direito (ATIENZA, 2013, p. 19). A primeira seria mais estrutural, da qual

Direitos Fundamentais e Justiça, da Revista Novos Estudos Jurídicos, entre outros. Coordenador do DASEIN - Núcleo de Estudos Hermenêuticos. E-mail: lenios@globomail.com

${ }^{2}$ Teses extraídas do texto Algunas tesis sobre el razonamiento judicial, de autoria de Manuel Atienza. 
cita como exemplo o normativismo, voltada para a conjuntura formal que constitui o sistema. A segunda seria mais funcional, como as posturas realistas e sociológicas, em que o olhar está centrado na prática jurídica concreta. A terceira partiria de uma projeção, uma idealidade do que deveria ser o Direito, como observa em algumas versões jusnaturalistas.

O jusfilósofo espanhol afirma que a construção teórica que articula não se enquadra exclusivamente em nenhuma das anteriores, mas tampouco as exclui. $\mathrm{Na}$ verdade, segundo diz, as pressupõe. Ao ressaltar a argumentação, não defende que esta represente o todo do direito, mas que esta dimensão tem assumido significativo relevo nas democracias contemporâneas, sendo o direito identificado como um conjunto de decisões e cadeias argumentativas que se antagonizam ou se conformam. Assim, parte de um modelo ideal, mas que não está a priori pronto, pois precisa ser constantemente adequado, e tudo isto com as circunstâncias já existentes. Deste modo, neste espaço intermediário, ele constrói sua TAJ, com importantes asserções sobre o raciocínio judicial e jurídico, que passo agora a enfrentar.

\section{Objeção a primeira tese de Atienza}

De início, Atienza afirma que o raciocínio judicial, apesar de importante, não representa o todo do raciocínio jurídico. Ademais, entende que, em geral, as teorias da argumentação jurídica limitaram-se a compreender o fenômeno como se este fosse apenas judicial. Como resultado, outras instâncias argumentativas do direito foram deixadas de lado, tais como a argumentação legislativa, advocatícia, dogmática/doutrinária e aquelas referentes à prova. Deste modo, o raciocínio jurídico converteu-se numa racionalidade estratégica. Em outra direção, o jurista espanhol entende que a argumentação jurídica deve abarcar outros tipos de diálogos, que precisam ser analisados de forma particular, pois possuem lógicas distintas.

A Crítica Hermenêutica do Direito acompanha esta tese. Os raciocínios que envolvem o fenômeno jurídico são diversos, sempre dependentes dos lugares de fala onde se encontram os falantes/ouvintes. Contudo, penso que a questão não seria "resolvida” com mais distinções (analíticas), ou seja, com repartições horizontais e superficiais do fenômeno. Isto é, precisamos agora de uma teoria da argumentação judicial, uma teoria da argumentação legislativa, uma teoria da argumentação advocatícia, uma teoria da argumentação doutrinária, e outras do tipo. Sendo todas estas interfaces da argumentação jurídica, como métodos e procedimentos próprios.

Em sentido contrário, a CHD procura fazer uma leitura prospectiva, na qual o discurso ganha em espessura e profundidade. $\mathrm{O}$ erro não está em limitar a racionalidade jurídica como se toda ela fosse um agir estratégico, mas em não reconhecer o caráter hermenêutico que a constitui em todas as suas facetas. A analítica procura sempre antecipar a realidade, para tentar operar com maior grau de certeza, porém, isto somente é possível com a suspensão da realidade para além do horizonte histórico, uma operação inversa daquela que o 
constitucionalismo contemporâneo, também chamado de neoconstitucionalismo, procurou fazer.

É inegável que a noção de constitucionalismo social teve a função de trazer para o âmbito da Constituição temas que antes eram reservados a esfera privada. Do mesmo modo que, é fácil perceber que o modo pelo qual o constitucionalismo do segundo pós-guerra fez público os espaços "reservados aos interesses privados", e essa publicização somente poderia ocorrer a partir do surgimento de uma materialidade, espaço que vem a ser ocupado pelos princípios. Com efeito, se o constitucionalismo altera (substancialmente) a teoria das fontes que sustenta o positivismo, e os princípios passam a propiciar uma nova teoria da norma (atrás de cada regra há, agora, um princípio que não a deixa "desacoplar" do mundo prático), é porque também o modelo de conhecimento subsuntivo, próprio do esquema sujeito-objeto, necessita ceder lugar a um novo paradigma interpretativo.

O contexto em que ocorre a invasão da filosofia pela linguagem (linguistic turn), é uma pos-metafísica de (re)inclusão da facticidad que, de forma impalpável, principalmente a partir da década de 50 do século passado, passou ao esquema sujeito-objeto (objetivista e subjetivista), estabelecendo uma circularidade virtuosa na compreensão. Desse modo, se vê um déficit de realidade produzido pelas posições epistemo-metodológicas mesmo presa ao esquema sujeito-objeto - vem a ser ocupado pelas posições interpretativas, especialmente as hermenêutico-ontológica, que deixou hipostática o método e procedimento, colocando no modo-de-ser e na facticidade o locus da compreensão. Assim, se salta do fundamentar (epistemológico) ao compreender (fenomenológico), onde o compreender não é mais uma ação do sujeito, mas sim um modo de ser que se dá em uma intersubjetividade. O novo constitucionalismo e a revolução copernicana proporcionada pela invasão da filosofia pela linguagem (do esquema sujeito-objeto para sujeito-sujeito) não apaga, entretanto, o feito de que vivemos, todavia, em um modo jurídico que busca exorcizar os feitos e conflitos tratados pelo direito, isto é, em um mundo em qual a metodologia jurídica continua com a função de estimular a desvinculação do caráter historicamente individualizado do caso que está em sua base, para alcançar o abstrato generalizado e comum, como bem alerta Castanheira Neves (NEVES, 2003, p. 287). Isto de um lado. De outro, nota-se que a operacionalidade do direito especialmente em países como Brasil aposta, cada vez mais, em teses empiristas ou voluntaristas que transformam juízes em legisladores. E, pior, a doutrina apoia esse tipo de avanço empirista (realismo jurídico). No fundo, a luta da CHD tem como inimigo o subjetivismo, porque é dele que decorre o discricionarismo e os diversos voluntarismos judiciais. Mariflor Aguilar Rivero (RIVERO, 2005, p. 41), professora mexicana, tem um interessante livro cujo título é Diálogo y Alteridad. Ela é radical, muito mais do que eu, na crítica ao subjetivismo. Ela tem uma pergunta genial: como se pode dar conta de um significado se este foi subjetivamente produzido e está mediado pela subjetividade do intérprete? Ela mostra que o ponto crucial para a hermenêutica é o combate à subjetividade. Por isso é que a hermenêutica se preocupa com o que vem antes da justificação/argumentação. 
Por outro lado, é necessário compreender que o direito - neste momento histórico - não é mais ordenador, como na etapa liberal; tampouco é (apenas) promotor, como era na etapa do welfare state; a verdade é que o direito nesta era do Estado Democrático de Direito é um plus normativo/qualitativo em relação as etapas anteriores, porque agora é transformador da realidade. E é exatamente por isso que aumenta sensivelmente a tensão em direção da grande inversão contra majoritária: a jurisdição constitucional, que, no Estado Democrático de Direito, vai se transformar no que vai garantir todos os direitos fundamentais-sociais e a própria democracia. Se efetivamente o constitucionalismo do Estado Democrático de Direito resgatou a "realidade perdida", de que modo a teoria jurídica reage perante este fenômeno? Como dar por vencido o modelo subsuntivo, que coloca o sujeito isolado do objeto? Como resolver a inexorável tensão entre fato e norma, separados, politicamente, pela Revolução Burguesa e, filosoficamente, pelas metafísicas (clássica e moderna)? E como resolver o problema das teorias que apostam no protagonismo dos juízes? De um modo ou de outro, até algumas teorias discursivas, a pretexto de superar as diversas formas assumidas pelo positivismo jurídico e procurar solucionar os problemas da impossibilidade de prever todas as hipóteses de aplicação própria de um direito que assumia um caráter inexoravelmente hermenêutico, apostaram na construção de discursos (prévios) de justificação/fundamentação (Begründungsdiskurs), com os que acabaram por incorrer na própria problemática que pretendiam criticar no positivismo. Não há dúvida, que esse novo modelo de justiça constitucional - o modelo de tribunais ad hoc introduzido strictu sensu a partir da Áustria e reafirmado nas Constituições da Itália, Alemanha, Portugal e Espanha, para falar apenas das principais -, deixa marcas indestrutíveis no constitucionalismo contemporâneo. Ou seja, não se pode falar em teoria do direito sem levar em conta o papel interventivo da jurisdição constitucional. E isso aumenta a necessidade de controle sobre as decisões.

A doutrina alemã, especialmente ela, em grande medida baseada no estudo da Lei Fundamental e da atuação do Tribunal Constitucional Federal (Bundesverfassungsgericht), influenciou todo o pensamento constitucional, momento em que ele se relaciona ao estudo da eficácia dos direitos fundamentais e dos mecanismos interpretativos que sustenta(va)m as teses que sucederão a ideia de forca normativa do texto constitucional e seu caratê dirigente ( dirigierende Verfassung).

Em outras palavras: as posturas positivistas (clássicas), ao separar o discurso jurídico do mundo prático, não encontraram adversário a altura em teses como a da teoria do discurso habermasiano, que deslocou o problema da atribuição de sentido para uma situação contra fática ideal de fala, cuja função é servir de justificação prévia ao procedimento de adequação entre facticidade e validade (e, portanto, superar a tensão entre fato e norma). No fundo, não houve grandes mudanças em relação à ameaça de teorias jurídicas enraizadas no esquema sujeito-objeto. Discursos de justificação prévia buscaram ultrapassar a decisão de origem, para alcançar todas as "situações semelhantes futuras." Ao mesmo tempo, para evitar decisionismos decorrentes do "ativismo judicial", procuraram aliviar o juiz da carga representada pelos problemas de fundamentação da norma que se aplica, ou vol.09, nº. 04, Rio de Janeiro, 2016.pp. 2207-2226 2211 
seja, a racionalidade da decisão (discursos de aplicação - Anwendungsdiskurs) do juiz já não depende do fundamento racional dessa norma, porque este "problema" já é resolvido por um discurso de fundamentação (anterior). Mas está claro que isso não acontece impunimente. A final, se fosse possível uma lei (um texto jurídico) prever todas as hipóteses de aplicação, estaríamos frente ao fenômeno da entificação metafísica dos sentidos. E isso não se corrige por "discursos de adequação", como propõem Günther Klaus e Jurgen Habermas, que nada mais fazem do que reconhecer a impossibilidade filosófica daquele que sustenta a sua própria tese.

É necessário compreender que nos movemos em uma impossibilidade de fazer coincidir texto e sentido do texto (norma), ou seja, nos movemos em uma impossibilidade de fazer coincidir discursos de validade e discursos de adequação. É neste ponto que se da o debate entre a hermenêutica (filosófica) e as diversas teorias discursivas. Objetivamente, não conseguimos alcançar um saber que pode abarcar todos os modos de aplicação dos textos jurídicos de uma vez. Em outras palavras, a objetividade conteria as hipóteses aplicativas, em que o texto conteria a norma, ou melhor ainda, o texto (a regra) conteria todas as normas (hipóteses de aplicação) possíveis. Se trabalharmos, no interior de um paradigma no qual o direito assumiu um caráter hermenêutico que resulta da própria característica que marcou o direito a partir do segundo pós-guerra, em que visivelmente a tradição nos mostra o papel intervencionista da jurisdição constitucional, então a preocupação de qualquer teoria jurídica deve estar direcionada ao enfrentamento das consequências desse fenómeno. Em poucas palavras: se o direito é um saber prático, a tarefa de qualquer teoria jurídica é buscar as condições para:

1. A concretização de direitos - a final, a Constituição (todavia) constitui - e,

2. Ao mesmo tempo evitar decisionismos e arbitrariedades interpretativas.

Se trata, de entender que, se o primeiro problema metodológico tem uma resposta a partir da superação do paradigma representacional, em que não se separa mais a interpretação da aplicação, o segundo parece muito mais fácil de solucionar, isto é, como evitar decisionismos, ativismos, etc., e alcançar uma resposta correta (que eu chamo de resposta adequada a Constituição) em cada caso. Este é o ponto da discussão hermenêutica.

\section{Objeção a segunda tese de Atienza}

Passa-se analisar à segunda tese de Atienza. Nesta, o jurista espanhol assevera que: "el razonamiento judicial, el que se expresa en las motivaciones de las sentencias, tiene esencialmente un carácter justificativo" (ATIENZA, 2013). O jurista denota que as teorias argumentativas procuram demonstrar como as decisones jurídicas devem ser justificadas, sendo seu trabalho uma reconstrução dos procedimentos de decisão já existentes.

Quanto ao caráter justificatório da decisão judicial, não divirjo. O raciocínio judicial não é um exercício categorial, por isso também refuto a subsunção. Contudo, tenho uma discordância, aqui. O modo como Atienza desenvolve a tese sustentaria a seguinte máxima: Primeiro posso decidir (ou escolher, para muitos) e depois 
justifico (argumentativamente). Ou seja, o olhar está voltado para o depois, como se antes houvesse o nada e, com a decisão, viesse a existir os sentidos que precisam apresentar-se razoavelmente concatenados em cadeias argumentativas. Parte-se de um paradigma de indeterminação que irá ser apenas minorado com a adequação a certos procedimentos, por isso também a aceitação da inexorabilidade de um nível de juízo discricional.

A Crítica Hermenêutica do Direito está preocupada com aquilo que vem antes. Não que ela não se preocupe com a argumentação, que é o modo como se explicita o que já se compreendeu. Mas a CHD tem como premissa que não se interpreta para compreender e, sim, compreende-se para interpretar. A tradição (Gadamer), os efeitos que o peso da história tem sobre nós, é algo que se torna a condição de possibilidade do processo de compreensão. Os sentidos não são imposições de um sujeito alheio à realidade circundante; ao contrário, resultam deste espaço intersubjetivo de significações. Assim, em meio a esta mundanidade, o compreender tornase uma vivência em que a separações analíticas entre descrição-explicação-justificação sempre chegam tarde. Em certo sentido, Atienza também reconhece esta fusão que as torna indissociáveis. Em suas palavras:

(...) "en el proceso real de la motivación judicial es imposible separar del todo el contexto del descubrimiento y el de justificación, porque las razones que explican pueden ser también razones que justifican" (ATIENZA, 2013).

Todavia, diferenciamo-nos quanto ao modo de entender isto que diz Atienza. O jurista espanhol procura contemplar isto em sua teoria da argumentação, mas entendo que isto é muito difícil. Para uma concepção hermenêutica, sempre há aquilo que se esconde, o não dito naquilo que se fala, de modo que a ânsia de depurar os discursos leva-nos a mais problemas e afastam-nos ainda mais de uma compreensão mais existencial para um campo lógico árido, diríamos, um espaço sem facticidade, atemporal, locus onde o positivismo levou o Direito. Parece que o fantasma do neopositivismo lógico sempre está presente nas teorias analítico-argumentativas. Antes dos conceitos, não há nada. $\mathrm{O}$ importante é definir conceitualmente aquilo que se pretende justificar.

Como olhamos o antes na determinação do agora, a decisão correta/adequada será bem (constitucionalmente) fundamentada e não apenas argumentativamente adequada, pois, caso contrário, corre-se o risco de o jurista contentar-se com uma retórica acerca do direito. Ou seja, corre-se o risco de deixar que o juiz faça a sua escolha, para, depois, contentarmo-nos com uma boa argumentação a favor de sua escolha. Ocorre que, antes deste segundo momento, a escolha pode ter sido incorreta. É por isso que a CHD preocupa-se com a decisão, que não pode ser um ato de escolha. Aqui me permito colocar o "dilema da ponte", que ajuda a explicar o problema do "decidir primeiro e fundamentar depois". Como posso atravessar o abismo gnosiológico do conhecimento, chegar do outro lado e depois retornar para construir a ponte pela qual eu já passei? Eis a questão. A ponte é condição de possibilidade. Ela é o fundamento. Por isso, para a hermenêutica (CHD), o juiz não decide para, só depois, buscar a fundamentação. Ele só decide porque tem a fundamentação que the é condição prévia. Caso contrário, caímos em um teleologismo. Decidir não pode ser um ato de vontade. 


\section{Objeção a terceira tese de Atienza}

A terceira tese defendida por Atienza diz: que "la distinción entre casos (judiciales) fáciles y difíciles y, correspondientemente, entre justificación interna y justificación externa es básicamente aceptable, pero necesita ser precisada y desarrollada”(ATIENZA, 2013).

Tenho referido que fazer distinção entre casos fáceis e casos dificeis já é um caso difícil. Para a CHD um caso é sempre um caso, a dificuldade não está nele, mas em nossa posição frente a ele. Assim, um caso fácil já foi difícil antes de ter sido compreendido. Um caso difícil é aquele que ainda não foi compreendido adequadamente. O que muda é o nosso conhecimento, mas não o caso em si. Complexas são as nossas maneiras e modos de alcançar a compreensão do fenômeno e não o próprio fenômeno. Assim, o maior problema é que desta distinção entre casos fáceis e difíceis extraem-se modos decisórios distintos.

Explico. Fazendo a distinção, Atienza defende que para os casos fáceis a subsunção já seria suficiente para resolver, o que não aconteceria com os casos difíceis. Em outras palavras, seria como se dissesse que para os casos fáceis valeria o Positivismo Exegético e a(s) teoria(s) argumentativa(s) serviriam para colmatar suas insuficiências nos casos difíceis. Em suas palavras:

"Lo que fundamentalmente quiere decirse con esa distinción es que existen algunos casos (la mayoría probablemente de los que llegan a los tribunales) que todos los juristas (o la mayoría, o los expertos una vez conocidos todos los detalles) resolverían de una misma manera, porque los datos normativos y los fácticos de los que depende la solución no ofrecen dudas. Justificar la decisión en relación con esos casos supone, por ello, efectuar una deducción cuyas premisas contendrían los anteriores datos y la conclusión sería un enunciado normativo singular (por ejemplo, "X debe ser condenado a la pena P") que llevará al juez (si no quiere incurrir en una contradicción pragmática) a decidir condenar a $\mathrm{X}$ a la pena P" (ATIENZA, 2013).

Concordo que esta distinção não é de natureza ontológica, não havendo nestes casos nada em si mesmos que os defina de modo peremptório. Todavia, parte de cisões estruturais que, por consequência, como disse, demandarão formas distintas de resolução. Isto fica evidente na seguinte citação de Atienza:

"De manera que el razonamiento judicial de carácter justificativo tiene tres formas de “justificación interna”: el silogismo subsuntivo; el silogismo práctico o finalista, si se trata de una regla de fin (cuyo esquema sería: "Se debe obtener el fin F; sólo si se realiza M se puede obtener F; por lo tanto, se debe realizar M"), y la ponderación, si se trata de princípios" (ATIENZA, 2013, p.21).

Para a CHD, todos os casos resolvem-se com um mesmo labor hermenêutico que reconstrói o direito em sua historicidade, ainda que em dimensões diferentes, a partir do (des)velamento da situação que interprete. Isso significa dizer que aqueles que acreditam na cisão casos fáceis/difíceis fazem um corte epistêmico no modo como apreendem a realidade? Poderíamos dizer, nessa linha, que quem acredita na subsunção para os casos fáceis é meio-positivista ou semi-positivista? Quem decide se o texto jurídico (lei) exige a subsunção ou a ponderação (ou outro nome que se dê a "raciocínios complexos")? Ao que tudo indica, a resposta é: o sujeito, a partir de sua 
subjetividade (consciência de si). Mas em que condições isso pode ocorrer? Por que para um intérprete "basta a subsunção" e, para outro, não? Eis as perguntas que devem ser respondidas por aqueles que (ainda) acreditam na cisão entre casos fáceis e casos difíceis.

Em poucas palavras: cindir casos fáceis de casos difíceis é admitir que um caso jurídico seja fácil “em si”. Mas, como afirmar que ele seja fácil, se, para tanto, devemos compreendê-lo? E um caso difícil, depois de compreendido, transforma-se em um caso fácil? Se é correto dizer isso, então um caso não é nem fácil, nem difícil. Ele depende da compreensão do intérprete. Só que essa compreensão não ocorre a partir do esquema sujeitoobjeto, uma vez que o círculo hermenêutico funciona como o elemento que supera tanto a adequatio intelectum et rei como a adequatio rei et intelectum. Daí a importância dos dois teoremas fundamentais da hermenêutica: a diferença ontológica e o círculo hermenêutico.

O que quero dizer é que a crise dos modelos interpretativos não autoriza que as teorias da argumentação ou outras teorias procedimentais venham a construir uma espécie de reserva hermenêutica, que somente seria chamada a atuar nos casos de "insuficiência" da regra, isto é, quando se estivesse frente a "casos dificeis" (hard cases). Casos fáceis e casos difíceis partem de um mesmo ponto e possuem em comum algo que é condição de possibilidade: a pré-comprrensãp. Esse equívoco de distinguir entre easy e hard cases, é cometido, tanto pelo positivismo de Hart como pelas teorias discursivo-argumentativas, como as de Atienza (ATIENZA, 2000). O que tem em comum é o fato de que, nos hard cases, se consideram que os princípios (critérios) para os resolver não se encontram no plano da aplicação, mas eles devem ser removidos de uma "história jurídica" que somente é possível no plano de discursos a priori (no fundo, discursos de fundamentação prévios). Também Dworkin fez indevidamente esta distinção entre casos fáceis e casos difíceis. Mas o fez - e justiça seja feita ao jusfilósofo norteamericano - por razões distintas, pois a diferença é que Dworkin não "exonera" os discursos de aplicação dos discursos de fundamentação, que dão prima face. $\mathrm{Na}$ verdade, como Gadamer, ele não distingue discursos de aplicação de discursos de fundamentação, assim como não separa interpretação e aplicação.

Crer na distinção (cisão) entre casos fáceis e casos difíceis é pensar que o direito se infere em uma "suficiência ôntica", ou seja, que a "completude" do mundo jurídico pode ser "resolvida" por raciocínios causaisexplicativos, em uma espécie de "positivismo da causalidade". Pensar assim é esquecer que essa "metafísica da causalidade" é apenas uma etapa necessária para chegar aos entes.

O que as teorias discursivo-argumentativas não levam em conta é que, antes da explicação causal (sequer o raciocínio subsuntivo dedutivo), há algo mais originário, e é condição de possibilidade de qualquer explicação causal. Se trata da pré-compreensão, da antecipação de sentido, onde o horizonte de sentido (prejuízos limita o processo de atribuição de sentido. Essa dimensão pré-compreensiva, forjada no mundo prático (facticidade) não é um elemento formal, traduzido por regras de argumentação, por exemplo, como se tratasse de um caminho para algo. 
Essa dimensão ocorre em uma totalidade de nossa realidade, a partir da conjunção de múltiplos aspectos existenciais, que fazem parte de nossa experiência (facticidade, modo-de-ser-no-mundo) e são, por tanto, elementos aos quais temos acesso por meio do esforço fenomenológico de explicitação. Partir de uma préelaboração do que seja um caso fácil ou difícil é incorrer no esquema sujeito-objeto, como se fosse possível ter um "nível zero de sentido", separando a pré-compreensão e tudo o que ela representa como condição para a compreensão de um problema. Não esquecemos que a discricionariedade interpretativa é fruto do paradigma da filosofia da consciência, e se fortalece na cisão entre interpretar e aplicar, o que implica na prevalência do dualismo sujeito-objeto. E essa discricionariedade/arbitrariedade positivista- sob os mais diversos trajes- ainda domina o modo-de-atuar dos juristas. Enquanto Dworkin considera a discricionariedade como antidemocrática, Hart vai dizer que o poder discricionário é o preço necessário que se tem que pagar para evitar o inconveniente de métodos alternativos de regulamentação desses litígios (casos difíceis). Por exemplo, o reenvio ao legislativo, assim as correntes positivistas podem não estar de acordo com a afirmação, Hart representa, na verdade, uma espécie de pensamento médio: há uma coisa em comum entre o positivismo e as diversas teorias da argumentação: a distinção/divisão "casos simples / casos complexos (fáceis e difíceis), o que demonstra a presença (e permanência) do paradigma da subjetividade, emergente do dualismo metafísico e do esquema sujeito-objeto.

\section{Objeção a quarta tese de Atienza}

A quarta tese do jurista espanhol refere-se à motivação das decisões judiciais que consistiria em oferecer boas razões organizadas na forma adequada para que seja possível a persuasão. A ideia é que as motivações precisam apresentar-se com um mínimo de explicitude e cumprir requisitos básicos. Apesar de falar de razões corretas, a ênfase volta-se para a forma. Isto é, deve apresentar-se com uma forma lógica reconhecível, mesmo reconhecendo que isto não é o mais importante. Ao final, busca-se a persuasão, utilizar-se adequadamente dos meios possíveis para consegui-la. A argumentação, aqui, ao meu sentir, aproxima-se perigosamente de um agir estratégico.

Quanto a requisitos mínimos para a explicitação não há dúvidas, todas as decisões devem tê-los, sob pena de serem passiveis de inexistirem. Contudo há um problema que já destaquei: o direito não é retórica. As análises que se centram nas formas acabam recaindo nesta aporia. Há sempre o risco de aceitar-se uma decisão errada, mas que se apresenta fundada em boas razões, sobretudo, quando o convencimento se torna um objetivo a ser alcançado. Este tipo de raciocínio fragiliza o direito, que pode tornar-se um amontoado de decisões particulares isto é, que não dialogam com a tradição - que visam persuadir a plateia/público. Nesse sentido, a justificação corre o risco de tornar-se uma argumentação retórica. E, com isso, seu nível de racionalidade diminui 
consideravelmente.

\section{Objeção a quinta tese de Atienza.}

Na tese de número 5, Atienza informa que:

"Una argumentación (justificación) judicial es un proceso que comienza con el planteamiento de un problema (casi siempre bivalente) y termina con una solución al mismo tiempo que se resuelve también con un "si" o un "no": se absuelve o se condena; se declara la constitucionalidad o la no constitucionalidad de un artículo de una ley; se acepta o no se acepta (o se acepta en tal aspecto, pero no en tal otro) el recurso de una de las partes del proceso; etc." (ATIENZA, 2013).

Sobre esta tese tenho muito pouco a falar, apenas a subscrevo. De fato, uma argumentação/justificação começa com um problema apresentado e que é quase sempre antagônico. Por isso mesmo, como decorrência, sua resolução "dará" o direito para apenas uma das partes. Apenas registraria que um caso jamais se apresenta como "um fato desvestido de direito". O caso já aparece juridicizado. Por isso Gadamer faz a crítica à separação da interpretação em três fases (as três subtilitas: intelligendi, explicandie applicandi). Para ele, tudo está em uma só: a applicatio. Interpretar é aplicar. Aqui, meu registro tem o intuito, não de discordar, mas de agregar valor à tese de Atienza. Mais ainda, acrescentaria a voz de um analítico como Tughendat, que reconhece a importância da hermenêutica, chamando a atenção para uma certa incapacidade de a filosofia analítica perceber uma dimensão prática como Heidegger fez, além de pregar a necessidade de um debate mais profícuo entre analíticos e continentais. A partir dele, transplantando para o direito - embora reconheça a dificuldade dessa tarefa - diria que uma decisão necessita de uma motivação não-arbitrária (o que já afastas todas as formas de decisionismo e escolhas arbitrárias). Uma justificação dessa posição, na medida em que todas as sentenças, ao levarem uma pretensão de verdade, referem-se a um contexto de justificação, isto é, exigem razões e contrarrazões e uma universalidade, ou seja, o alcance do decidido para situações semelhantes (TUGHENDAT, 1975).

\section{Objeção a sexta tese de Atienza}

Na sexta tese, o jurista espanhol adverte que "en materia de prueba, el papel de la teoría de la argumentación jurídica consiste fundamentalmente en aclarar nociones básicas y en advertir sobre la comisión de una serie de errores frecuentes"(ATIENZA, 2013).

Nesta tese, Atienza pontua que em muitos espaços a questão "dos fatos" seria resolvida com uma livre e boa motivação. Isto como uma decorrência de um consenso de que nesta área estaríamos diante de argumentos indutivos, sendo a conclusão, destes, apenas provável, mas não necessária. Em caminho oposto, o jurista refuta esta limitação, pois acredita que um argumento de forma indutiva, com premissas sólidas, tenha uma conclusão com maior certeza do que um argumento dedutivo com premissas duvidosas. Ademais, considera que em matéria de 
provas deveria haver maior abertura para o conhecimento científico. Por fim, defende que no raciocínio probatório é essencial ter em conta o marco institucional.

Desta última consideração, aproximamo-nos em demasia. A Crítica Hermenêutica do Direito tem defendido a retirada, dos códigos civil e penal, dos termos "livre convencimento" e "livre apreciação da prova" no Brasil. Trata-se de um resquício do solipsismo presente desde o passado, em Oskar Büllow. Os estragos que isso já fez no Brasil são incalculáveis. O primeiro - o livre convencimento - foi retirado quando da edição do novo Código de Processo Civil de 2015 e o segundo ainda persiste no projeto do Código de Processo Penal. O ponto não é simples. Não é apenas um problema de nomenclatura, os juízes não são livres, sua decisão é um ato de responsabilidade política (Dworkin). Imerso numa comunidade em que os sentidos são dados, estes vínculos têm que ser respeitados na avaliação probatória. Se Atienza diz que em matéria de prova a teoria da argumentação serve para aclarar noções básicas e advertir erros, diria que a CHD serviria para demonstrar de que modo o sujeito (juiz) não é livre em sua apreciação.

\section{Objeção a sétima tese de Atienza}

Na sétima tese, Atienza enuncia que:

"En un sentido amplio de la expresión (el de la tradición hermenéutica) toda la práctica del Derecho tiene un carácter interpretativo. Pero lo que los juristas suelen entender por problema de interpretación es un tipo específico de cuestión cuya solución requiere de diversas formas y técnicas de razonamiento necesariamente presididas por una teoría no sólo general, sino también normativa del Derecho" (ATIENZA, 2013).

Nesta tese, Atienza nos diz que o caráter interpretativo do Direito é uma decorrência deste - o Direito não ser natural, mas uma criação humana. Assim, para o compreendermos, tal com um jogo, deveríamos nos posicionar como participantes e não como meros espectadores. Num sentido mais estrito, afirma que os problemas interpretativos se manifestam devido aos problemas linguísticos seja dos seus sentidos ou sobre o modo como os textos foram redigidos. Destes cita os seguintes: 1) imprecisão; 2) lacunas e contradições; 3) a relação entre o dito e o que se queria dizer; 4) o conflito entre o texto e sua finalidade; e 5) dúvidas acerca da (melhor) harmonização do texto com o ordenamento jurídico como um todo. Atienza reconhece que pensar apenas em técnicas interpretativas é insuficiente, devendo haver uma teoria da interpretação que as acomode, não apenas num nível descritivo e instrumental, mas também normativo. Esta teoria seria parte integrante da teoria da argumentação jurídica. Como exemplo traz Ronald Dworkin. A pergunta que faço é: seria isto possível? Integrar Dworkin dentro de uma teoria da argumentação? Jogar Dworkin nos braços da analítica?

Penso que esta seria uma tarefa muito difícil. Na verdade, impossível. Quando dizemos que o direito é um fenômeno interpretativo estamos afirmando que ele é aquilo que é emanado pelas instituições jurídicas, sendo que as questões a ele relativas encontram, necessariamente, respostas nas leis, nos princípios constitucionais, nos 
regulamentos e nos precedentes que tenham DNA constitucional, e não na vontade individual do aplicador (mesmo que seja uma Corte Constitucional). E isto se dá num processo hermenêutico existencial de um ser-nomundo que se constitui com os demais. Assim, a interpretação do direito deixa de ser uma técnica e torna-se uma explicitação do compreendido. Neste aspecto uma teoria da argumentação poderia ser um auxiliar, ou melhor um complemento - algo com enfoque para o modo de se explicitar, mas sem se dissociar do que vem antes. Dito de outra forma, uma teoria interpretativa inserida numa TAJ poderia implodi-la, tendo em vista a rígida estrutura que procura "disciplinar" o discurso. De novo, é importante diferenciar a analítica da hermenêutica. E a hermenêutica da analítica.

\section{Objeção a oitava tese de Atienza}

$\mathrm{Na}$ oitava tese Atienza faz uma ode à ponderação, como um procedimento que deveria consistir num senso/sentido comum que os juízes deveriam subscrever, pois seria inevitável para certos casos, o que os afastaria da arbitrariedade.

Atienza sustenta a relevância da ponderação - para os casos difíceis - na linha proposta por Alexy, diante da lacuna legislativa ou de um resultado moralmente questionável. Assim, nesta realidade as duas fases deveriam ser desenvolvidas, sendo na primeira gerada uma regra que antes inexistia no sistema e, na segunda na qual essa será aplicada por subsunção ao caso. Mesmo reconhecendo as limitações metodológicas, como a atribuição de valores na "formula de peso", o jurista apresenta a ponderação como um método que deveria ser incorporado nas decisões judiciais.

De início, vale destacar que lanço dúvidas sobre o caráter meramente descritivo ou prescritivo da teoria de Alexy. Até hoje nunca vi um caso que tenha feito todo o processo que ele apresenta, com todas as suas etapas, cálculos e coisas do tipo. A posteriori, vejo decisões explicadas a partir de seu modelo. Sendo assim, teríamos apenas mais uma ferramenta analítica que nada diz sobre como deve ser o raciocínio judicial. Porém, acredito que esta não seja a intenção do jurista alemão. No Brasil - e isso acontece em outros países também - o que se tem visto é os juízes simplesmente contraporem um principio a outro e dizerem que estão fazendo "ponderação". Claro que não é o que Atienza defende, mas esse registro sobre o que acontece nas práticas jurídicas deve ser feito. Até mesmo o Tribunal Constitucional alemão simplifica a ponderação, isso quando não o fez sem nem falar sobre Alexy ou teorias correlatas.

Com relação à tese da ponderação, a Crítica Hermenêutica do Direito manifesta sua total contrariedade. Delinearei minha discordância: como é sabido, a falta de concretização das Constituições programáticas demandou uma reformulação na teoria dos princípios, representada pelo abandono do chamado critério fraco de diferenciação (que considera princípio e regra com a mesma estrutura lógica hipotético-condicional e com 
diferentes densidades semânticas) para a adoção do critério forte de distinção, no qual os princípios assumiam estrutura lógica diferente daquela que identificava a regra. Isso colocou os princípios sob o manto metodológico da ponderação (enquanto que a regra se mantinha na subsunção), permitiu novas possibilidades para os princípios e não demorou muito para que estivéssemos falando em aplicação direta mediante ponderação controlada pela proporcionalidade, principalmente como foi recepcionada no Brasil. Mas o fato é que esse giro não conferiu ao princípio suficiência ôntico-semântica, além de ter mantido intacto o erro originário: $o$ mundo prático foi jogado para "dentro" do sistema e, a partir dessa operação, pensado como tal (como sistema). Ou seja, o mundo prático que é concreto ou, na falta de uma melhor palavra, pragmático, paradoxalmente é retratado ao modo da "abstratalidade" própria da ideia de sistema. A percepção originária de que os princípios não possuíam densidade semântica conteve, bem ou mal, o avanço do "pamprincipiologismo", mas o equívoco no diagnóstico da crise fez com que os princípios elevassem o grau de discricionariedade, decisionismo e arbitrariedade. A problemática do uso da ponderação ${ }^{3}$ agrava-se com a sua extensão às regras ${ }^{4}$.

De todo modo, o problema principal da ponderação é a sua filiação ao esquema sujeito-objeto e a sua dependência da discricionariedade, ratio final. Desse modo, se a discricionariedade é o elemento que sustenta o positivismo jurídico nos casos difíceis e nas vaguezas e ambiguidades da linguagem dos textos jurídicos, não parece que a ponderação seja "o" mecanismo que livre (ou arranque) o direito dos braços do positivismo. Ao contrário, a ponderação não deixa de ser a repristinação - agora de forma sofisticada - da discricionariedade e de suas variações. Veja-se: a teoria da argumentação - da qual surgiu a ponderação - não conseguiu fugir do velho problema engendrado pelo subjetivismo, a discricionariedade, circunstância que é reconhecida pelo próprio Alexy (ALEXY, 2008, p. 611). Esta que vai desde quando se reconhece ou não um caso difícil, na escolha dos princípios conflitantes, na valoração dos pesos, e outros do tipo. A questão é como a discricionariedade não é vencida, tampouco minorada, mas disfarçada com sofisticação lógica.

E tem mais um problema na teoria alexiana e que tem relação com a ponderação, por comissão ou omissão. É que, paradoxalmente, Alexy leva para dentro da sua teoria a famosa "Fórmula Radbruch" que refere, em linhas gerais, que o Direito, ainda que injusto, tem validade jurídica. No entanto, o Direito que for extremamente injusto deixa de ser Direito, e perde, assim, sua validade. Se analisarmos essa fórmula sob a ótica da distância temporal, veremos que ela tem uma razão de ser. Explico: Radbruch viveu os tempos mais duros em termos de violação aos direitos fundamentais de toda a Europa. E Alexy, décadas mais tarde, ressuscita-a e utiliza-a como forma de defender a posição tomada pelo Tribunal Constitucional alemão no caso dos atiradores do muro de

\footnotetext{
${ }^{3}$ No modo como a ponderação vem sendo convocada (e "aplicada”) em terrae brasilis, tudo está a indicar que não passa daquilo que Philipp Heck chamava, na Jurisprudência dos Interesses, de Abwägung, que quer dizer "sopesamento", "balanceamento" ou "ponderação". Com a diferença de que, na Interessenjurisprudenz, não havia a construção da "regra da ponderação".

${ }^{4}$ Por todos, vale mencionar Humberto Ávila (ÁVILA, 2009), Luís Roberto Barroso e Ana Paula Barcellos (BARROSO; BARCELLOS, 2003), que sustentam a possibilidade de ponderação de regras.
} 
Berlim (Mauerschützen) que condenou os agentes da antiga Alemanha Oriental. O que parece não explicado por Alexy é saber qual o parâmetro para se analisar quando uma lei é "apenas injusta" ou "extremamente injusta", que pode acabar gerando um convite à discricionariedade.

Esse apelo à fórmula Radbruch é um recuo em direção ao jusnaturalismo. Injustiça extrema é um conceito anêmico. Quando digo que esse apelo à fórmula radbrucheana é um paradoxo, quero dizer que para alguém que se diz não-positivista como Alexy, embora um não-positivista inclusivo, não parece muito sistemático dar esse salto para trás, justamente envolvendo uma correção moral do direito. Qualquer não-positivista ou antipositivista não admitiria uma correção moral. Mesmo que o epíteto "inclusivo" denotasse uma complementariedade entre direito e moral, ainda assim os positivistas "inclusivistas" exigiriam um pedigree para identificar o modo como se pode dizer que, moralmente, determinada lei é extremamente injusta a ponto de ser expungida do direito. Temo que isso seja uma espécie de ornitorrinco teórico-jurídico. A questão que não fica clara em Alexy é que, ao lançar mão da fórmula Radbruch, ele dispensa a ponderação; ou, neste caso, a ponderação dispensa a próprio modelo estabelecido pelo seu criador (adequação, necessidade e proporcionalidade em sentido estrito)?

De todo modo, o apoio de Atienza à ponderação passa ao largo das próprias fragilidades da teoria alexiana, exatamente porque sua preocupação não implica dividir o direito em dimensão ideal e dimensão real, em que a dimensão ideal é a moral.

\section{Objeção a nona tese de Atienza}

Na nona tese, Atienza discute a relação entre Direito e Moralidade. Em suas palavras:

"La noción de buena motivación (o de motivación sin más) implica que existen ecessári objetivos para evaluar los argumentos judiciales de tipo justificativo. ¿Pero se trata de ecessári puramente formales o tienen también uma alcance ecessária? ¿Suponen alguna referencia a la moral y, uma particular, la ecessár de uma objetivismo moral mínimo? ¿Son esos ecessári suficientes para sustentar la tesis de la única respuesta correcta uma alguna de sus versiones? Uma respuesta positiva a eces cuestiones es condición ecessária para tomarse la motivación judicial uma serio y presupone uma concepción no positivista del Derecho"(ATIENZA, 2013).

Atienza apresenta a interessante ideia de que se não existissem critérios objetivos para avaliar as motivações, expostas em argumentos justificativos, então as decisões não poderiam ser criticadas, seriam únicas e infalíveis. Todavia, a prática judicial demonstra o contrário. A questão torna-se complexa nos casos difíceis em que apareceriam critérios de racionalidade prática como universalidade, coerência, adequação das consequências, moral social, moral crítica e razoabilidade. A pergunta que o jurista faz é: com base nestes chegamos a uma (única) resposta correta? A resposta que dá é bem menos forte do que se pensa, pois como a maioria dos casos que o direito resolve são situações que se apresentam entre duas possibilidades antagônicas (culpado/inocente; 
válido/inválido; etc.) seria razoável pensar que uma destas terá maior sustentação. Se esta perspectiva for pensada como não positivista, como consequência, terá também que sustentar um objetivismo moral mínimo.

Este é mais um ponto de aproximação. Neste aspecto, Atienza caminha nos limites do modelo teórico analítico, abrindo diálogo com a moralidade, que tradicionalmente foi tida como um conhecimento não objetivo. Diria que para ser uma concepção não positivista, não apenas é necessário reconhecer um mínimo de objetivismo - ou melhor, objetividade - moral, que, na CHD, chamamos de um mínimo "é", mas também estabelecer algum tipo de vínculo. A CHD apropria-se da tese habermasiana de cooriginariedade entre direito e moral. O filosofo de Frankfurt reconhece que os dois sistemas normativos são complementares, sendo uma relação de natureza sociológica. Em essa união as duas partes são beneficiadas, a moral em seu déficit de eficácia e o direito com sua falta de legitimidade. Assim, para Habermas o sistema jurídico somente é legítimo quando não contrário aos princípios morais. Não obstante, isto não é suficiente para sua legitimidade, que também requer razões éticopolíticas e pragmáticas. Antes da tensão entre facticidade e validade, as normas jurídicas devem manifestar a vontade discursiva dos cidadãos, que por consequência, não são apenas seus destinatários. Neste processo, a gênese do direito ocorre sob razões morais. Essa tese contraria toda a tradição juspositivista que desde a separação entre fato e valor não aceita uma relação necessária entre direito e moral. Assim, os sentidos jurídicos já se dão com uma legitimidade moral que hermeneuticamente são sempre atualizados.

Contudo, é importante destacar que é possível fazer uma distinção entre objetividade do argumento moral e objetivismo moral. Este último é carregado por um sentido histórico que não pode simplesmente ser interrompido por desejo de seu intérprete ou articulador. A linguagem carrega consigo a tradição. É possível, em alguns casos, desligar os elos da tradição a partir de interpretações que operem, hermeneuticamente, na forma da destruição e da (re)construção. Mas há aqui uma série de questões metodológicas envolvidas e que precisam ser explicitadas. Assim, de que modo seria possível falar em objetivismo sem associar o conceito ao realismo filosófico, à metafísica clássica, à ontoteologia, a outros desse tipo? E nesse aspecto não acompanho o professor espanhol. Ora, parece-me plenamente possível defender a objetividade de um argumento moral (do tipo "a tortura é um ato atroz") sem afirmar que se trata de um objetivismo moral. Afinal, a objetividade também é uma questão hermenêutica.

\section{Objeção a décima tese de Atienza}

Na décima e última tese, Atienza defende que:

"La argumentación puede considerarse como un método de resolución de problemas y, por ello, en la elaboración de un argumento judicial justificativo (de una motivación) es útil distinguir las siguientes fases: identificación y análisis del problema; propuesta de una solución; comprobación y revisión; redacción de un texto"(ATIENZA, 2013). 
Por fim, na última tese o jurista apresenta a argumentação como um método de resolução de problemas. Tenho que concordar parcialmente com esta afirmação. A argumentação é importante, mas não é tudo. Para a CHD a linguagem apresenta-se em dois níveis complementares, o nível hermenêutico, pré-teórico, existencial, no qual a compreensão acontece; e o nível apofântico, no qual a explicitação do compreendido se manifesta, diria que este espaço seria o argumentativo. Desta forma, uma TAJ pode ser considerada um método que resolve problemas deste horizonte. Todavia, a maiorias das propostas discursivas não contempla o nível hermenêutico e, assim, acreditam que os procedimentos logicamente estruturados darão conta de todo o processo. E quando isso acontece, temos mais problemas do que soluções. O problema da interpretação/aplicação do Direito não é um problema de precisão de linguagem. Argumentar não é o mesmo que compreender. O compreender vem sempre antes. Se uma TAJ contenta-se com o argumentar/justificar, corre o risco de perder o controle sobre o objeto: a lei e a Constituição.

\section{PALAVRAS FINAIS}

Como reconhecido no início deste artigo, também na conclusão é necessário dizer da inestimável contribuição do professor Atienza para a Filosofia do Direito, para além dos seus limites nacionais. Todavia, como estamos sob paradigmas filosóficos distintos, por mais que existam algumas aproximações, existem também muitas divergências, que entendo enriquecer o debate acadêmico. E aqui foram apresentadas e debatidas, respeitosamente.

Quando falo de hermenêutica, procuro situá-la no interior do(s) paradigma(s) filosófico(s), considerando as duas metafísicas e o giro ontológico-linguístico proporcionado por Heidegger, Gadamer e também, de algum modo, por Wittgenstein, pela importância que dá a linguagem pública. Sempre falamos de um determinado lugar. A hermenêutica fala desse terceiro paradigma. Lorenz Puntel explica bem que, quando fazemos filosofia, fazemos teoria. E que teoria pressupõe um quadro referencial teórico que permita articular os seus resultados em um contexto de sistematicidade (PUNTEL, 1978). Ernildo Stein afirma algo similar, mas chama esse contexto amplo que acomoda a sistematicidade da reflexão de paradigmas filosóficos. Falar de um determinado lugar implica compromissos.

Diria que "é ontologicamente impossível querer mais analítica e menos hermenêutica 5". Atienza incorre em um problema hermenêutico ao procurar o sentido da parte conferindo pouca (ou menos) importância ao todo. Faltou o círculo hermenêutico. Quando afirmo ser ontologicamente impossível querer mais analítica que hermenêutica, obviamente - mas obviamente mesmo - estou a me referir à ontologia fundamental, ou

\footnotetext{
${ }^{5}$ Uma resposta à seguinte afirmação de Atienza dada numa entrevista: “(...) eu diria que a filosofia do Direito brasileira necessita de menos hermenêutica e mais filosofia analítica”. Disponível em: http://www.conjur.com.br/2015-set-05/entrevista-manuelatienza-professor-universidade-alicante Acesso em: 02/06/2016.
} 
analítica existencial. Supomos aqui que há, digamos, uma pré-compreensão já sedimentada sobre esse assunto. Com efeito, mesmo na tradição analítica um autor do porte de Ernst Tugendhat reconhece um acerto decisivo na descrição realizada por Heidegger em Ser e Tempo a respeito da relação entre autoconsciência e autodeterminação. Ontologia fundamental significa: a descrição fenomenológica do ente que possui o privilégio, entre todos os outros, de compreender o ser. Ou seja, estamos falando de compreender. Estamos falando em círculo da compreensão, logo, círculo hermenêutico. Se estamos falando em ser, estamos falando de ontologia. Não da ontologia clássica, objetivista.

Por certo que essa compreensão precisa ser explicitada. E a explicitação envolve processos e estruturas que são de natureza analítica: há questões lógicas, epistemológicas e argumentativas que, obviamente, são relevantes. Não existe uma importância maior da dimensão compreensiva profunda (logos hermenêutico) com relação à dimensão mostrativa ou explicitativa, analítica, argumentativa e outras do tipo. (logos apofântico). Não se trata de dizer o que importa mais; ou o que é mais necessário. Há um privilégio ontológico da dimensão hermenêutica por causa da relação circular da compreensão.

Ouso afirmar, também, que a analítica, sem hermenêutica, fica frágil e diminui de tamanho no plano epistêmico. Veja-se: não se está a dizer que a analítica é desimportante. Isso porque nenhuma argumentação se dá num vácuo de sentido. O restante apenas complementa o nosso raciocínio. Como diz o filósofo gaúcho Ernildo Stein em seu livro Aproximações sobre Hermenêutica: "A analítica sem a hermenêutica é vazia e a hermenêutica sem a analítica é cega" (STEIN, 2002.p.451). Eis um ponto que devemos levar em consideração.

A questão "teoria da argumentação versus hermenêutica" e os aspectos positivistas que podem ser notados em alguns autores argumentativistas (a discricionariedade do ponderador ou do preenchimento da dogmática dos espaços-quadro em Alexy, por exemplo) são questóes que necessitam ser tratadas. Destaco apenas que outros autores, como é o caso de Paul Ricoeur, procuram apontar para as diferenças entre uma teoria interpretativa (mais hermenêutica, portanto) e uma teoria argumentativa. Kaufmann deixa isso bem claro também. Ricoeur afirma que a teoria de Dworkin, embora use recorrentemente o termo argumento, é uma teoria interpretativa, e não argumentativa. Isso porque, diferentemente da teoria de Robert Alexy, por exemplo, que possui a característica de reivindicar para a prática argumentativa geral a qualidade de Begründung, ou seja, de fundamentação, Dworkin está muito mais interessado no horizonte político-ético no qual se desdobra a prática interpretativa do Direito. Para ele, afirma Ricoeur, "o Direito é inseparável de uma teoria política substantiva. É esse interesse último que, afinal, o afasta de uma teoria formal da argumentação jurídica”. Assim, não é que Dworkin focaliza o aspecto "técnico" da interpretação jurídica (sic); é que, para tratar de questões substantivas, como o são as questões de moralidade, de política e jurídicas, o que importa é assumir a responsabilidade de identificar e promover o valor de cada um desses domínios — e isso é uma questão primariamente hermenêutica. 
De todo o exposto, a Crítica Hermenêutica do Direito mantém-se aberta ao diálogo, pois, como diria Gadamer: "a conversação que está em curso subtrai-se a qualquer fixação. Seria um mau hermeneuta aquele que imaginasse poder ou dever ter a última palavra" (GADAMER, 2004, p. 544).

\title{
CRITICAL HERMENEUTICS OF LAW AND THE THEORY OF ARGUMENTATION OF ATIENZA: CONVERGENCES AND DIVERGENCES ON THE LEGAL REASONING
}

\begin{abstract}
Think about the legal reasoning is a necessary and ongoing task for lawyers, especially for legal theorists. Thus, and with great emphasis are the reflections of Manuel Atienza. His theory of legal reasoning (TAJ) is presented as one of the most important theoretical models within an analytical tradition of law analysis. For all that, the existence of a dialogue on their thinking is enriching to broaden the perspectives of different viewpoints. Critical Hermeneutics of Law (CHD) that developed is located on another floor. Starting from philosophical contributions of hermeneutic phenomenology that observes the legal hermeneutic as a phenomenon which presupposes an intersubjective space of meanings. By being in different philosophical paradigms, CHD and TAJ already has a basic antagonism, however, some approximations are also possible. In this text will be raised some differences and similarities between the two theoretical projects whose main themes, among others: a) the analytical and argumentative reasoning; b) weighting; c) the legal argument as a rhetorical exercise; and d) the court order and morality influences.
\end{abstract}

Keywords: Critical Hermeneutics of Law; Theory of legal argument; analytical and argumentative reasoning; weighting; Judicial decision.

\section{REFERENCIAS}

ALEXY, Robert. Teoria dos Direitos Fundamentais. Trad. Luis Virgilio A. Silva. São Paulo: Malheiros, 2008.

ATIENZA, Manuel. As razões do direito. Teorias da argumentação jurídica. São Paulo: Landy, 2002.

"Argumentación jurídica”. In: El derecho y la justicia. Madri: Trota, 2000.

Curso de Argumentação Jurídica. Madri: Editorial Trota, 2013.

El sentido del Derecho. Barcelona: Editorial Ariel, 2003.

ÁVILA, Humberto. Teoria dos princípios. 9. ed. São Paulo: Malheiros, 2009.

BARROSO, Luís Roberto; BARCELLOS, Ana Paula. O começo da história: a nova interpretação constitucional e o papel dos princípios no direito brasileiro. In: BARROSO, Luís Roberto. A nova interpretação constitucional: ponderação, direitos fundamentais e relações privadas. Rio de Janeiro: Renovar, 2003.

GADAMER, Hans-Gerog. Verdade e Método. II. 2 ed. Petrópolis: Vozes, 2004.

NEVES, Antonio Castanheira. O actual problema metodológico da interpretação jurídica. Coimbra: Coimbra Editores, 2003. 
PUNTEL, Lorenz. Grundlagen einer Theorie der Wahrheit. W. de Gruyter, Berlin/New York 1990.

Wahrheitstheorien in der neueren Philosophie. Eine kritisch-systematische Darstellung. Wissenschaftliche Buchgesellschaft, Darmstadt 1978; Auflage 1993;

Grundlagen einer Theorie der Wahrheit. W. de Gruyter, Berlin/New York 1990.

RIVERO, Mariflor Aguilar. Diálogo y alteridad. Trazos de la hermenéutica de Gadamer. Ciudad de México, Paideia-Unam, 2005.

STEIN, Ernildo. Tarefas da desconstrução - anamorfose e profundidades - ilusões da interpretação na obra de Heidegger in: Fenomenologia hoje II: significado e linguagem. Organizadores: Ricardo Timm de Souza e Nythamar Fernandes de Oliveira. Porto Alegre, EDIPUCRS, 2002.

STRECK, Lenio Luiz. Hermenéutica y Decisión Judicial. 1a ed. Bogotá: Pontificia Universidad Javeriana, Facultad de Ciencias Jurídicas: Grupo Editorial Ibáñez, 2012.

Decision Juridica y Poder Judicial: un debate acerca de la autonomía de Derecho. Editora: Editorial Academica Espanola, 2015.

TUGHENDAT, Ernst. Vorlesungen zur Einführung in die sprachanalytische Philosophie. Suhrkamp, Frankfurt am Main, 1975.

Trabalho enviado em 19 de setembro de 2016.

Aceito em 01 de novembro de 2016. 